\title{
RANCANG BANGUN SISTEM REM MOBIL LISTRIK FUSENA
}

\author{
Fauzan Ilham Maulana ${ }^{1}$, Noorsakti Wahyudi ${ }^{2}$, Indah Puspitasari ${ }^{3}$ \\ Progam Studi Mesin Otomotif, Jurusan Teknik, Politeknik Negeri Madiun \\ Jalan Serayu No. 84 Madiun, 63133 \\ e-mail: ${ }^{1}$ fauzan.ilham.maulana@gmail.com, ${ }^{2}$ noorsakti@pnm.ac.id, ${ }^{3}$ indahpuspitasari@pnm.ac.id
}

\begin{abstract}
The brake system is a device to slow down or stop the movement of the wheel automatically so that the vehicle will move slowly. This completeness in the vehicle is very important and vital because it functions as a safety for life in driving. In the process of making the Electric Car Fusena brake system has steps in the process, consists of size planning, materials used, designs realized, manufacturing brake system supporting components, assembly, installation and testing of brake systems. The Fusena Electric Car brake system use a disc-type hydraulic brake system with one brake master that can work simultaneous with dual circuit fluids (front and rear braking). The comparison of the brake pedal is changed to 3: 1, designing and recreating the caliper stand to make it more precise so that it gets maximum brake performance and is better than the system used before. Static testing of the Fusena Electric Car hydraulic brake system is done by positioning the vehicle on an inclined plane at a slope of $15^{\circ}$ and $20^{\circ}$ with a variable driver load of $40 \mathrm{~kg}, 50 \mathrm{~kg}, 60 \mathrm{~kg}$ and $70 \mathrm{~kg}$. The test results are that the vehicle does not experience displacement or movement. And the results of the average dynamic test of the Brake System at a speed of $27.3 \mathrm{~km} / \mathrm{h}$ with an average braking distance of $171 \mathrm{~cm}=1.71$ meters and the average deceleration time is 0.26 seconds.
\end{abstract}

Key words: Hydraulic Brake System, Optimization, Fusena Electric Car

\begin{abstract}
ABSTRAK
Sistem rem adalah suatu piranti untuk memperlambat atau menghentikan gerakan roda secara otomatis sehingga kendaraan akan bergerak menjadi pelan. Kelengkapan ini pada kendaraan sangat penting dan vital karena berfungsi sebagai pengaman keselamatan jiwa dalam berkendara. Dalam proses pembuatan sistem rem Mobil Listrik Fusena memiliki tahapan dalam pengerjaannya, berupa perencanaan ukuran, bahan yang digunakan, desain yang direalisasikan, pembuatan komponen penunjang system rem, perakitan, pemasangan dan pengujian sistem rem. Sistem rem Mobil Listrik Fusena menggunakan sistem rem hidrolis tipe cakram dengan satu master rem yang dapat bekerja secara bersamaan dengan fluida sirkuit ganda (depan dan belakang). Perbandingan pedal rem diubah menjadi 3 : 1, mendesain dan membuat ulang dudukan caliper agar lebih presisi sehingga mendapatkan kinerja rem yang maksimal dan lebih baik dari sistem yang dipakai sebelumnya. Pengujian statis sistem rem hidrolis Mobil Listrik Fusena dilakukan dengan memposisikan kendaraan pada bidang miring di kemiringan $15^{\circ}$ dan $20^{\circ}$ dengan variabel beban pengemudi $40 \mathrm{~kg}, 50 \mathrm{~kg}, 60 \mathrm{~kg}$, dan $70 \mathrm{~kg}$. Hasil pengujiannya adalah kendaraan tidak mengalami perpindahan atau pergerakan. Dan hasil rata-rata pengujian dinamis sistem rem pada kecepatan $27,3 \mathrm{~km} / \mathrm{jam}$ dengan jarak pengereman rata-rata adalah $171 \mathrm{~cm}=1,71$ meter dan rata-rata waktu deselerasi adalah 0,26 detik.
\end{abstract}

Kata kunci : Sistem Rem Hidrolik, Optimasi, Mobil Listrik Fusena

\section{PENDAHULUAN}

Di Indonesia salah satu faktor utama penyebab kecelakaan adalah kelalaian pengemudi dalam mengendalikan kendaraannya, yaitu penggunaan sistem rem yang kurang tepat. Sistem rem merupakan faktor penting dalam berkendara, khususnya untuk keamanan dan upaya penghematan bahan bakar. Sehingga penyusun tertarik untuk ikut serta dalam upaya pengembangan kendaraan yang efisien dan aman untuk dikendarai serta dapat bersaing di kompetisi nasional yakni Kompetisi Mobil Listrik Indonesia (KMLI).

Pada tahun 2017, Khanafi Tamam membuat sistem rem yang diterapkan pada mobil listrik Pancanaka dengan 
hasil menggunakan tiga disc brake dengan konfigurasi dua disc brake di kedua roda depan dan satu disc brake diporos roda belakang dengan memakai satu master rem dan hasil pengeremanya mencapai jarak rata-rata 4,495 m pada kecepatan rata-rata 24,95 $\mathrm{km} / \mathrm{jam}$. Kekurangan penelitian ini adalah jarak antara caliper dan dudukan knuckle yang kurang presisi sehingga mengakibatkan adanya gesekan terhadap disc brake dengan brake pad saat pedal rem tidak ditekan, pemilihan bahan komponen yang kurang baik, dan sistem rem tersebut menggunakan perbandingan tuas pedal rem $1: 1$, akibatnya membutuhkan tenaga lebih besar saat menginjak pedal rem untuk dapat menghentikan kendaraan.

Pada penelitian ini dirancang untuk memecahkan permasalahan tersebut dengan cara mengoptimasi sistem rem agar menghasilkan kinerja pengereman yang baik, dapat menciptakan pengendalian mobil yang baik dan aman yaitu dengan merubah perbandingan tuas pedal rem menjadi $3: 1$, menggunakan empat disc brake dengan konfigurasi dua disc brake dimasingmasing roda depan dan dua disc brake di kedua roda belakang kendaraan dan mengguanakan bahan komponen sistem rem yang baik dengan memperhatikan regulasi dari KMLI. Optimasi tersebut akan dievaluasi dan direvisi sesuai regulasi yang sudah ditentukan pada perlombaan Kompetisi Mobil Listrik Indonesia (KMLI). Tujuan dari optimasi sistem rem mobil listrik Fusena adalah mendapatkan hasil kinerja sistem rem yang lebih baik dari sistem rem yang dipakai sebelumnya. Penyusun tertarik untuk ikut serta dalam upaya pengembangan kendaraan yang hemat energi, ramah lingkungan, efisien dan aman untuk dikendarai serta dapat bersaing di kompetisi nasional.

\section{METODE PENELITIAN}

Mobil Listrik Fusena menggunakan tipe aliran fluida sirkuit gandadepanbelakang, sirkuit dibagi menjadi dua yakni kedua roda depan dan kedua roda belakang. Kelebihan aliran fluida rem tipe ini adalah gaya pengereman yang merata. Adapun desain dari beberapa komponen sistem rem pada Mobil Listrik Fusena adalah sebagai berikut:

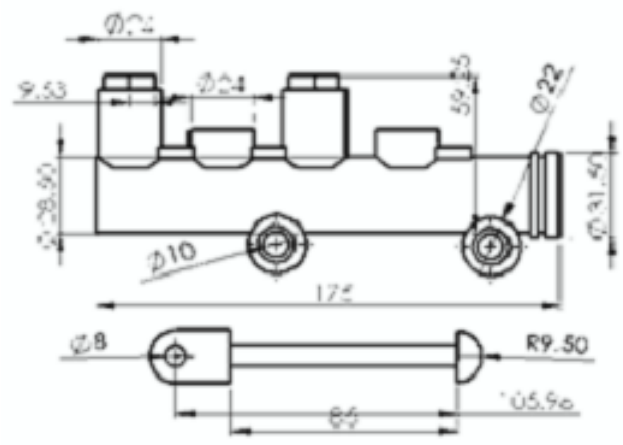

Gambar 1. Desain master rem

Master rem yang digunakan adalah jenis double piston dengan satu reservoir (tempat penampung minyak rem).

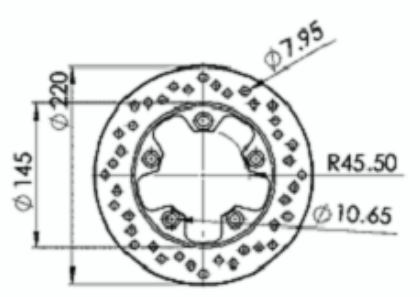

Gambar 2. Desain disc brake

Disc brake yang digunakan adalah jenis ventilated disc type, terdapat lubanglubang pada sebagian besar bagian disc yang berfungsi sebagai pendinginan agar tidak terjadi fading.

Tipe caliper yang digunakan adalah fixed caliper type (double Piston), pada jenis ini terdapat dua piston. 


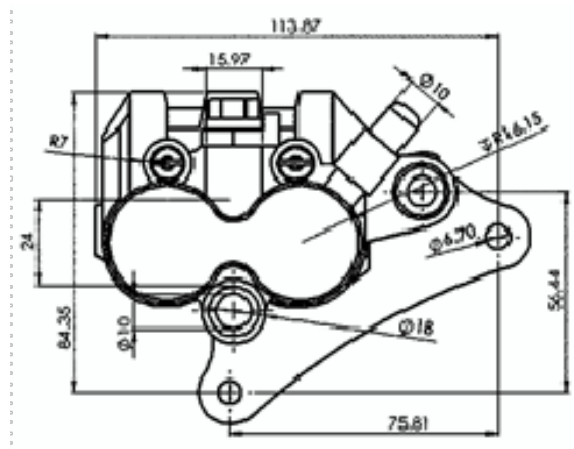

Gambar 3. Desain caliper rem

Langkah terakhir adalah proses penelitian dan proses pengujian yang dilakukan secara statis dan dinamis. Pengujian statis sistem rem dilakukan padakemiringan $15^{\circ}$ dan $20^{\circ}$. Pengujian dinamis sistem rem dengan melakukan akselerasi penuh pada jarak $30 \mathrm{~m}$ kemudian melakukan deselerasi/ pengereman penuh guna mendapatkan jarak dan waktu pengereman kendaraan.

\section{HASIL dan PEMBAHASAN}

Pada tahap pengujian yang dilakukan terhadap "Optimasi Sistem Rem Mobil Listrik Fusena” ini, bertujuan untuk mengetahui hasil kinerja sistem rem dan menganalisa kerja sistem rem.

\section{Pengujian Statis Sistem Rem}

Tujuan pengujian ini adalah untuk mengetahui kemampuan sistem rem saat kendaraan berada pada posisi kemiringan $15^{\circ}$ dan $20^{\circ}$ dengan variabel beban pada kendaraan yang berbeda yaitu $40 \mathrm{~kg}, 50 \mathrm{~kg}, 60 \mathrm{~kg}$, dan $70 \mathrm{~kg}$.

Pengujian statis sistem rem dengan sudut kemiringan $15^{\circ}$

Pada pengujian rem statis dilakukan dengan menempatkan kendaraan pada kemiringan $15^{\circ}$ dan $20^{\circ}$, serta dinaiki oleh penumpang dengan variabel beban pengemudi $40 \mathrm{~kg}, 50 \mathrm{~kg}, 60 \mathrm{~kg}$ dan 70 kg. Tujuan pengujian ini dimaksudkan untuk menguji pengereman seluruh roda pada beragam variabel tiap kemiringan yang telah ditentukan agar tidak mengalami pergeseran/pergerakan saat dilakukan pengereman.

Tabel 1. Hasil pengujian statis pada kemiringan $15^{\circ}$

\begin{tabular}{|c|c|c|c|c|c|}
\hline \multirow{2}{*}{$\begin{array}{c}\text { Sudut } \\
\text { Kemiri } \\
\text { ngan }\end{array}$} & \multirow{2}{*}{$\begin{array}{c}\text { Beban } \\
\text { pengemudi } \\
(\mathrm{kg})\end{array}$} & \multicolumn{3}{|c|}{$\begin{array}{c}\text { Perpindahan } \\
\text { Jarak (cm) }\end{array}$} & \multirow{2}{*}{$\begin{array}{l}\text { Rata- } \\
\text { Rata } \\
(\mathrm{cm})\end{array}$} \\
\hline & & I & II & III & \\
\hline \multirow{4}{*}{$15^{\circ}$} & 40 & 0 & 0 & 0 & 0 \\
\hline & 50 & 0 & 0 & 0 & 0 \\
\hline & 60 & 0 & 0 & 0 & 0 \\
\hline & 70 & 0 & 0 & 0 & 0 \\
\hline
\end{tabular}

Dari hasil pengujian dengan sudut kemiringan $15^{\circ}$ dengan variabel beban pengemudi yang berbeda-beda, tidak mengalami perpindahan/ pergeseran pada mobil listrik Fusena.

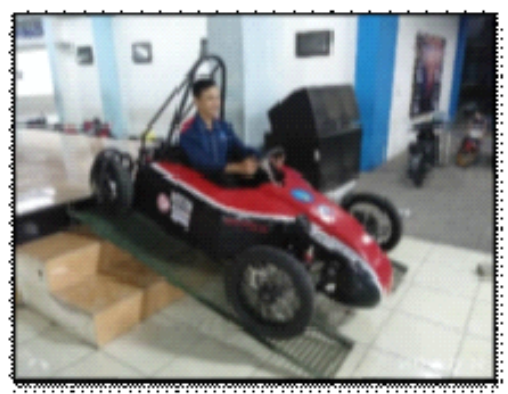

Gambar 4. Proses pengujian statis sistem rem pada sudut kemiringan $15^{\circ}$

Pengujian statis sistem rem dengan sudut kemiringan $20^{\circ}$

Setelah melakukan uji statis sistem rem pada kemiringan $15^{\circ}$, selanjutnya melakukan pengujian statis sistem rem pada kemiringan $20^{\circ}$, dengan alat, bahan dan cara yang sama pada pengujian sebelumnya (kemiringan $15^{\circ}$ ).

Adapun hal yang berbeda adalah proses penentuan ketinggian papan alas pengujian diposisi $20^{\circ}$. Selanjutnya melakukan pengukuran ulang menggunakan smartphone sesuai langkah pada sudut kemiringan $15^{\circ}$.

Dari hasil pengujian dengan sudut kemiringan $20^{\circ}$ dengan variabel beban pengemudi yang berbeda-beda yang dilakukan sebanyak tiga kali, tidak mengalami perpindahan/pergeseran. Sistem rem dalam kondisi baik dan aman. 
Tabel 2. Hasil pengujian statis pada kemiringan $20^{\circ}$

\begin{tabular}{|c|c|c|c|c|c|}
\hline \multirow{2}{*}{$\begin{array}{c}\text { Sudut } \\
\text { Kemiri } \\
\text { ngan }\end{array}$} & \multirow{2}{*}{$\begin{array}{c}\text { Beban } \\
\text { pengemu } \\
\text { di (kg) }\end{array}$} & \multicolumn{3}{|c|}{$\begin{array}{c}\text { Perpindahan } \\
\text { Jarak (cm) }\end{array}$} & \multirow{2}{*}{$\begin{array}{l}\text { Rata- } \\
\text { Rata } \\
(\mathrm{cm})\end{array}$} \\
\hline & & I & II & III & \\
\hline \multirow{4}{*}{$20^{\circ}$} & 40 & 0 & 0 & 0 & 0 \\
\hline & 50 & 0 & 0 & 0 & 0 \\
\hline & 60 & 0 & 0 & 0 & 0 \\
\hline & 70 & 0 & 0 & 0 & 0 \\
\hline
\end{tabular}

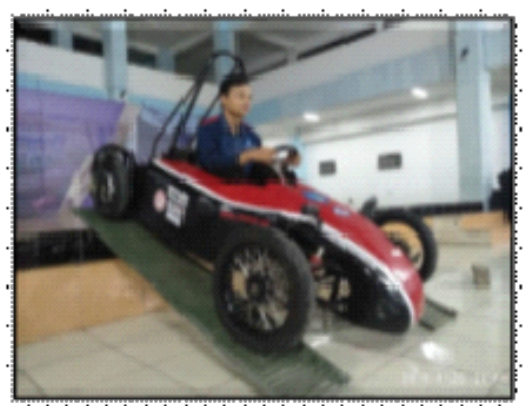

Gambar 5. Proses pengujian statis sistem rem pada sudut kemiringan $20^{\circ}$

\section{Pengujian dinamis sistem rem}

Pada pengujian rem dinamis dilakukan dengan beban pengemudi $70 \mathrm{~kg}$, dengan dua variabel kondisi jalan yakni kondisi kering dan jalan basah. Pengujian dimaksudkan untuk menguji pengereman di seluruh roda setelah melakukan percepatan dari garis start sampai garis finish apakah sesuai dengan regulasi KMLI. Hal ini bertujuan untuk mendapatkan nilai terbaik yang diraih saat penilaian/ kategori uji akselerasi dan deselerasi (percepatan dan pengereman).

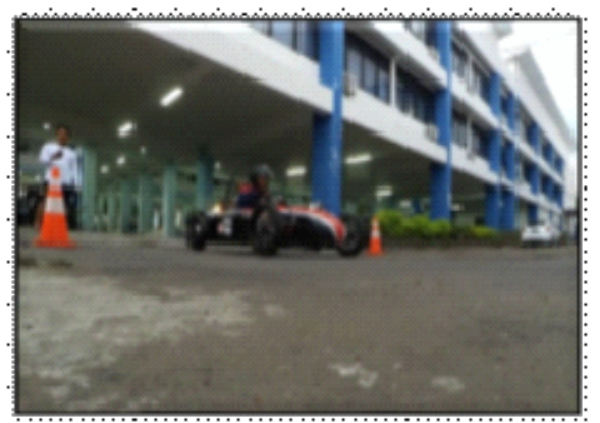

Gambar 6. Proses pengujian dinamis sistem rem (akselerasi)

Pengujian dinamis sistem rem kondisi jalan kering

Diawali dengan melakukan akselerasi (percepatan) penuh dari garis start sampai garis finish, lalu melakukan deselerasi (pengereman) setelah bagian paling depan kendaraan melewati garis finish. Saat kendaraan mencapai garis finish tim stopwatch siap mengukur waktu deselerasi sampai kendaraan berhenti total dan setelahnya disambut dengan persiapan tim pengukur jarak pengereman.

Tabel 3. Hasil pengujian dinamis pada kondisi jalan kering

\begin{tabular}{|c|c|c|c|}
\hline \multirow{2}{*}{$\begin{array}{c}\text { Pengu } \\
\text { jian }\end{array}$} & Akselerasi & \multicolumn{2}{|c|}{ Deselerasi } \\
\cline { 2 - 4 } & $\begin{array}{c}\text { Kecepatan } \\
(\mathrm{km} / \mathrm{jam})\end{array}$ & $\begin{array}{c}\text { Jarak } \\
\text { Pengereman } \\
(\mathrm{m})\end{array}$ & $\begin{array}{c}\text { Waktu } \\
\text { Tem } \\
\text { puh } \\
(\mathrm{s})\end{array}$ \\
\hline I & 28,3 & 1,84 & 0,36 \\
\hline II & 27,7 & 1,74 & 0,30 \\
\hline III & 27,1 & 1,66 & 0,21 \\
\hline $\begin{array}{c}\text { Rata- } \\
\text { Rata }\end{array}$ & 27,7 & 1,74 & 0,29 \\
\hline
\end{tabular}

Hasil pengujian dinamis sistem rem kondisi jalan kering dengan rata-rata kecepatan tempuh 27,7 km/jam dengan jarak pengereman rata-rata adalah 174 $\mathrm{cm}=1,74 \mathrm{~m}$ dan waktu deselerasi ratarata adalah 0,29 detik.

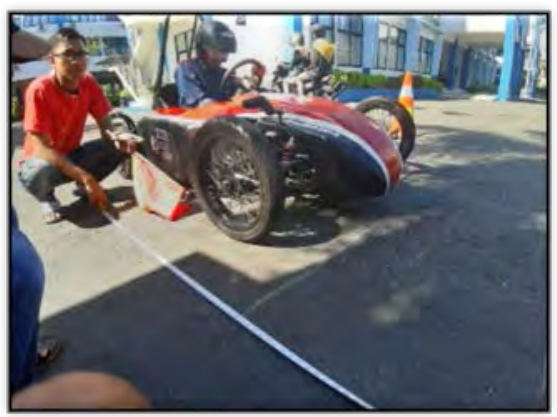

Gambar 7. Proses pengujian dinamis sistem rem kondisi jalan kering

Pengujian dinamis sistem rem kondisi jalan basah

Proses pengujian jalan basah, sama seperti pengujian dinamis pada kondisi jalan kering. Perbedaan berada pada kondisi jalan yang basah karena sebelumnya disiram menggunakan air di mulai dari garis start sampai garis finish dan area pengereman. 
Tabel 4. Hasil pengujian dinamis pada kondisi jalan basah

\begin{tabular}{|c|c|c|c|}
\hline \multirow[b]{2}{*}{$\begin{array}{l}\text { Pengu } \\
\text { jian }\end{array}$} & Akselerasi & \multicolumn{2}{|c|}{ Deselerasi } \\
\hline & $\begin{array}{c}\text { Kecepatan } \\
\text { (km/jam) }\end{array}$ & $\begin{array}{c}\text { Jarak } \\
\text { Pengere } \\
\text { man (m) }\end{array}$ & $\begin{array}{c}\text { Waktu } \\
\text { Tempuh } \\
\text { (s) }\end{array}$ \\
\hline $\mathrm{I}$ & 27,5 & 1,72 & 0,33 \\
\hline II & 26,9 & 1,69 & 0,21 \\
\hline III & 26,3 & 1,65 & 0,20 \\
\hline $\begin{array}{c}\text { Rata- } \\
\text { Rata }\end{array}$ & 27,7 & 1,68 & 0,24 \\
\hline
\end{tabular}

Hasil pengujian dinamis sistem rem kondisi jalan kering dengan rata-rata kecepatan tempuh 26,9 km/jam dengan jarak pengereman rata-rata $168 \mathrm{~cm}=$ 1,68 m dan waktu deselerasi rata - rata adalah 0,24 detik.

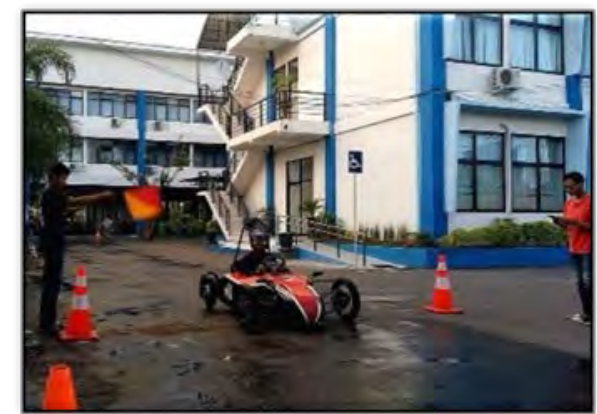

Gambar 8. Proses pengujian dinamis pada kondisi jalan basah

\section{Pengujian dinamis sistem rem}

Hasil pengujian dinamis sistem rem kondisi jalan kering dengan rata-rata kecepatan tempuh 27,7 km/jam dengan jarak pengereman adalah $174 \mathrm{~cm}=$ $1,74 \mathrm{~m}$ dan rata-rata waktu deselerasi adalah 0,29 detik. Dan hasil pengujian dinamis sistem rem kondisi jalan kering dengan rata-rata kecepatan tempuh 26,9 $\mathrm{km} / \mathrm{jam}$ dengan jarak pengereman ratarata adalah $168 \mathrm{~cm}=1,68 \mathrm{~m}$ dan waktu deselerasi adalah 0,24 detik.

Dari Tabel 5 dapat disimpulkan hasil rata-rata pengujian dinamis Sistem Rem pada kecepatan 27,3 km/jam dengan jarak pengereman rata- ata adalah $171 \mathrm{~cm}=1,71$ meter dan ratarata waktu deselerasi adalah 0,26 detik.
Berikut adalah rata-rata hasil pengujian Dinamis Sistem Rem :

Tabel 5. Hasil rata-rata pengujian dinamis sistem rem

\begin{tabular}{|c|c|c|c|}
\hline \multirow{2}{*}{$\begin{array}{c}\text { Pengujian } \\
\text { (Rata- } \\
\text { Rata) }\end{array}$} & \multirow{2}{*}{$\begin{array}{c}\text { Akselera } \\
\text { si } \\
\text { Kecepa } \\
\text { tan } \\
(\mathrm{km} / \mathrm{jam})\end{array}$} & \multicolumn{2}{|c|}{ Deselerasi } \\
\hline & & $\begin{array}{c}\text { Jarak } \\
\text { Pengere } \\
\text { man (m) }\end{array}$ & $\begin{array}{c}\text { Waktu } \\
\text { Tempuh } \\
\text { (s) }\end{array}$ \\
\hline $\begin{array}{c}\text { Jalan } \\
\text { Kering }\end{array}$ & 27,7 & 1,74 & 0,29 \\
\hline $\begin{array}{l}\text { Jalan } \\
\text { Basah }\end{array}$ & 26,9 & 1,69 & 0,24 \\
\hline Rata-Rata & 27,3 & 1,71 & 0,26 \\
\hline
\end{tabular}

\section{Hasil Keseluruhan Pengujian Sistem Rem}

Sistem rem pada mobil listrik Fusena menggunakan rem cakram tipe hidrolis dengan satu master rem yang dapat bekerja secara bersamaan dengan aliran fluida sirkuit ganda (depan - belakang). Proses optimasi yang dilakukan adalah mengubah perbandingan pedal rem menjadi 3 : 1 , penggantian komponen caliper dengan komponen original, dan meminimalkan gesekan antara kampas rem dengan piringan rem dengan mendesain dan membuat ulang dudukan caliper agar lebih presisi sehingga kinerja sistem pengereman menjadi lebih baik dari pengereman yang dipakai sebelumnya.

Pada pengujian statis dengan kemiringan $15^{\circ}$ dan $20^{\circ}$ dan dengan variabel pembebanan $40 \mathrm{~kg}, 50 \mathrm{~kg}, 60$ $\mathrm{kg}$, dan $70 \mathrm{~kg}$ pengereman roda dapat bekerja dengan baik tanpa terjadi pergeseran saat dilakukan pengujian secara berulang-ulang dengan variabel beban tersebut. Hasil rata-rata pengujian dinamis Sistem Rem pada kecepatan 27,3 km/jam dengan jarak pengereman rata-rata adalah $171 \mathrm{~cm}=$ 1,71 meter dan rata-rata waktu deselerasi adalah 0,26 detik. Pengujian tersebut telah dilakukan berulang-ulang dan didapatkan data hasil akhir terbaik sesuai data di atas. Selain itu, perbedaan hasil pengujian dinamis dipengaruhi oleh seberapa besar tekanan (gaya) dan 
respon yang diberikan oleh pengemudi saat melakukan pengereman atau deselerasi, jenis jalan yang digunakan dalam pengujian serta jenis tumpuan/ban yang digunakan pada saat pengujian sistem rem.

\section{KESIMPULAN}

Dari serangkaian perancanaan, pembuatan, dan pengujian sistem rem pada Mobil Listrik Fusena maka dapat disimpulkan bahwa sistem rem menggunakan rem cakram tipe hidrolis dengan satu master rem yang dapat bekerja secara bersamaan dengan aliran fluida sirkuit ganda (depan - belakang). Proses optimasi yang dilakukan adalah mengubah perbandingan pedal rem menjadi 3 : 1 , penggantian komponen caliper dengan komponen original, dan meminimalkan gesekan antara kampas rem dengan piringan rem dengan mendesain dan membuat ulang dudukan caliper agar lebih presisi sehingga didapatkan pengereman yang baik pada mobil listrik Fusena.

Pada pengujian statis dengan kemiringan $15^{\circ}$ dan $20^{\circ}$ dan dengan variabel pembebanan $40 \mathrm{~kg}, 50 \mathrm{~kg}, 60$ $\mathrm{kg}$, dan $70 \mathrm{~kg}$ pengereman roda dapat bekerja dengan baik tanpa terjadi dinamis didapatkan kecepatan rata-rata $27,3 \mathrm{~km} / \mathrm{jam}$ dengan jarak pengereman rata- rata sepanjang 1,71 meter dan ratarata waktu deselerasi adalah 0,26 detik. Hasil tersebut sangat baik bila dibandingkan dengan hasil penelitian sebelumnya.

\section{DAFTAR PUSTAKA}

[1] Herdianto, Agustinus. 2014. Perancangan Sistem Kemudi, Sistem Rem, dan Roda Urban City Car Untuk Kompetisi Urbanconcept Shell Eco-Marathon. Surabaya: Universitas Kristen Petra.

[2] Pedoman Kompetisi Mobil Listrik Indonesia KE-10 (KMLI X). 2018. Pedoman Kompetisi Mobil Listrik Indonesia Ke-10. Bandung: Politeknik Nergeri Bandung.

[3] Sihombing, Adolf $\mathrm{H}$ dan Rudy. 2015. Analisa Sistem Rem Kendaraan Pada Mobil Murah (Low Cost Green Car) Jenis B100RA-GMQFJ, Sumatra Utara: Universitas Pancasila.

[4] Sularso, Kiyokatsu Suga. 1997. Dasar Perencanaan dan Pemeliharaan Elemen Mesin. Jakarta : PT Pradnya Paramita.

[5] Tamam, Khanafi. 2017. Pembuatan Sistem Kemudi dan Sistem Rem Pada Mobil Listrik Pancanaka. Madiun: Politeknik Negeri Madiun. 